Supplement of Earth Syst. Dynam., 10, 473-484, 2019

https://doi.org/10.5194/esd-10-473-2019-supplement

(C) Author(s) 2019. This work is distributed under

the Creative Commons Attribution 4.0 License.

Earth System

Dynamics

(c) (i)

Supplement of

\title{
Different response of surface temperature and air temperature to deforestation in climate models
}

Johannes Winckler et al.

Correspondence to: Julia Pongratz (julia.pongratz@geographie.uni-muenchen.de)

The copyright of individual parts of the supplement might differ from the CC BY 4.0 License. 


\section{Overview}

7 Table S1: Inter-model comparison of the local effects, spatially averaged values.

$\therefore$ Figure[S1 Map indicating where deforestation is applied in the MPI- ESM simulations.

9 FigureS2 Zonal means of deforestation-induced annual mean temperature changes in the MPI-ESM.

Figure S3. $\Delta \mathrm{T}_{2 \mathrm{~m}} / \Delta \mathrm{T}_{\text {surf }}$ to illustrate where the annual mean $2 \mathrm{~m}$-air temperature and the surface 11 temperature respond differently in the MPI-ESM.

12 Figure $\mathrm{S} 4$. $\mathrm{T}_{\text {surf }}-\mathrm{T}_{\mathrm{atm}}$ as a measure of near-surface atmospheric instability, separately for nighttime 13 and daytime conditions.

14 Figure S5 Illustration temperature at different heights over grasslands and forests.

15 Figures $\mathrm{S6}$ S8 Maps corresponding to the inter-model comparison of the local effects.

16 Figure S9 Maps of the local effects on daytime and nighttime temperature for DJF and JJA. 


\begin{tabular}{|c|c|c|c|c|c|c|c|c|c|}
\hline Model & & 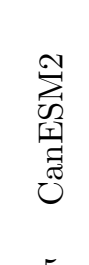 & $\sum_{0}^{+\infty}$ & 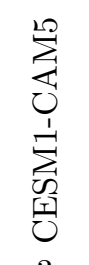 & 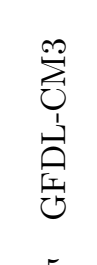 & 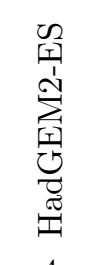 & 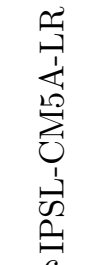 & 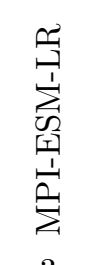 & 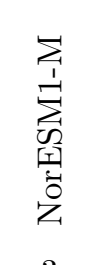 \\
\hline \# ens & & 5 & 6 & 3 & 5 & 4 & 6 & 3 & 3 \\
\hline \multirow[t]{3}{*}{ DJF } & $\Delta \mathrm{T}_{2 \mathrm{~m}}$ & -0.50 & -0.28 & -0.25 & -0.14 & -0.59 & -0.22 & -0.33 & -0.32 \\
\hline & $\Delta \mathrm{T}_{\text {surf }}$ & 0.72 & -0.45 & -0.44 & -0.13 & -0.71 & -0.31 & -0.40 & -0.46 \\
\hline & $\Delta \mathrm{T}_{2 \mathrm{~m}} / \Delta \mathrm{T}_{\text {surf }}$ & -0.69 & 0.62 & 0.56 & 1.11 & 0.82 & 0.71 & 0.83 & 0.70 \\
\hline \multirow[t]{3}{*}{ JJA } & $\Delta \mathrm{T}_{2 \mathrm{~m}}$ & 0.33 & 0.22 & 0.23 & 0.26 & -0.27 & 0.09 & 0.06 & 0.12 \\
\hline & $\Delta \mathrm{T}_{\text {surf }}$ & 0.60 & 0.40 & 0.35 & 0.74 & -0.13 & 0.19 & 0.18 & 0.23 \\
\hline & $\Delta T_{2 m} / \Delta T_{\text {surf }}$ & 0.55 & 0.56 & 0.66 & 0.35 & 2.15 & 0.45 & 0.36 & 0.54 \\
\hline
\end{tabular}

Table S1: Numerical values for the inter-model comparison of the local effects in Fig. 3. In every model, the difference between 30-year means of the 'historical' simulations of CMIP5 are analyzed. The number of available ensemble members for the 'historical' simulations (\# ens) differs across the models. In every model, we cut the 'pi-Control' simulations into 6 time slices of 30 years. For instance, in the MPI-ESM we then analyze $3 \times 6=18$ combinations of 'historical' and 'piControl'. Analogous to Fig. 3, the values shown here denote the local deforestation response averaged over mid-latitude areas $\left(40-60^{\circ} \mathrm{N}\right)$ that experienced intense deforestation $(\geq 15 \%)$, and the maps from which these averages are obtained are shown in Figs. $\mathrm{S} 7$ and $\mathrm{S} 8$. Shown are winter (DJF) and summer months (JJA) separately for near-surface air temperature $\left(\Delta \mathrm{T}_{2 \mathrm{~m}}\right)$, surface temperature $\left(\Delta \mathrm{T}_{\text {surf }}\right)$, and the ratio between the two $\left(\Delta \mathrm{T}_{2 \mathrm{~m}} / \Delta \mathrm{T}_{\text {surf }}\right)$.
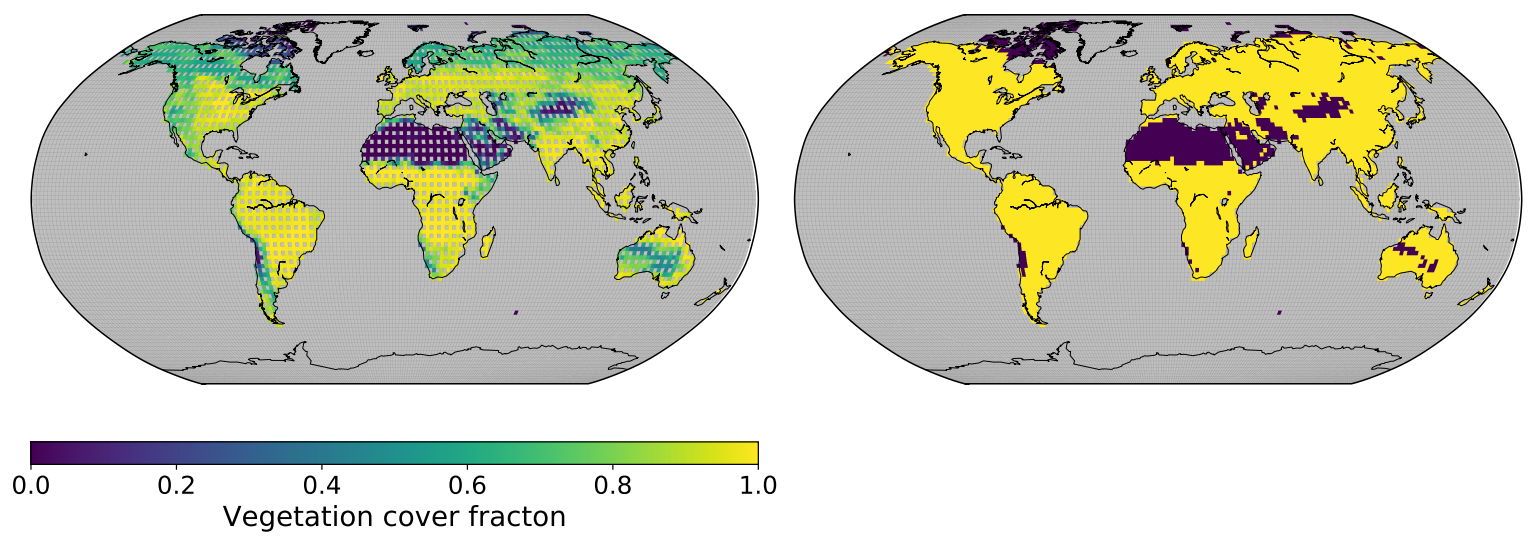

Figure S1: Map showing the fraction to which grid cells can potentially be covered with vegetation (after Pongratz et al. (2008)). From this, the map of the 'forest world' underlying our simulations is constructed by replacing in 3 out of 4 grid cells the non-forest vegetated part by forest; in the 4 th grid cell (gray) the vegetation distribution of the forest world is left unchanged.

Right: This map underlies the zonal averages shown in Fig. S2. The yellow color indicates grid cells where in the left map the vegetation cover fraction is larger than 50\% - only these grid cells are used for averaging. In all other grid cells, vegetation cover is less than $50 \%$. 

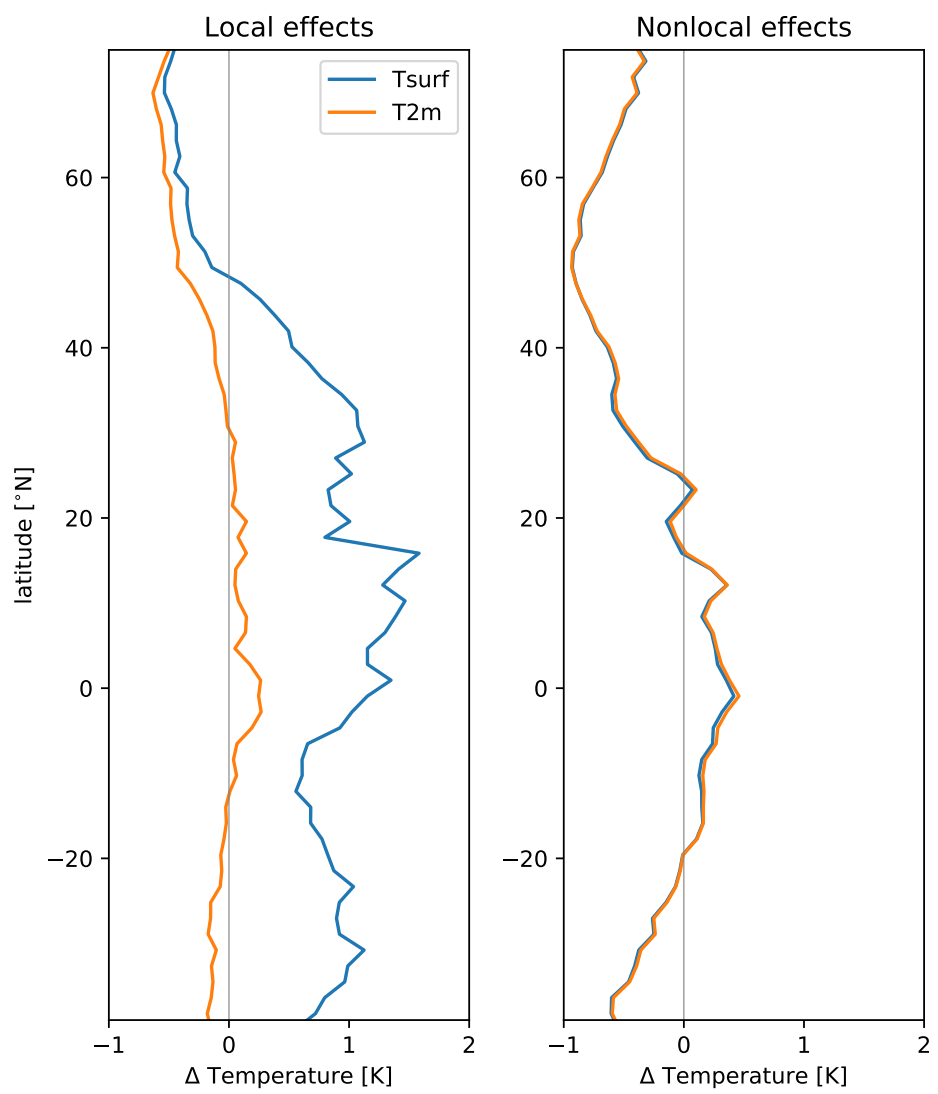

Figure S2: Zonal averages of changes in annual mean temperature for deforestation in 3 of 4 grid boxes in the MPI-ESM. Values are averaged over areas in which more than $50 \%$ of a grid box is covered by vegetation. The deforestation grid boxes and the areas that are used for the zonal averages are shown in Fig. S1.
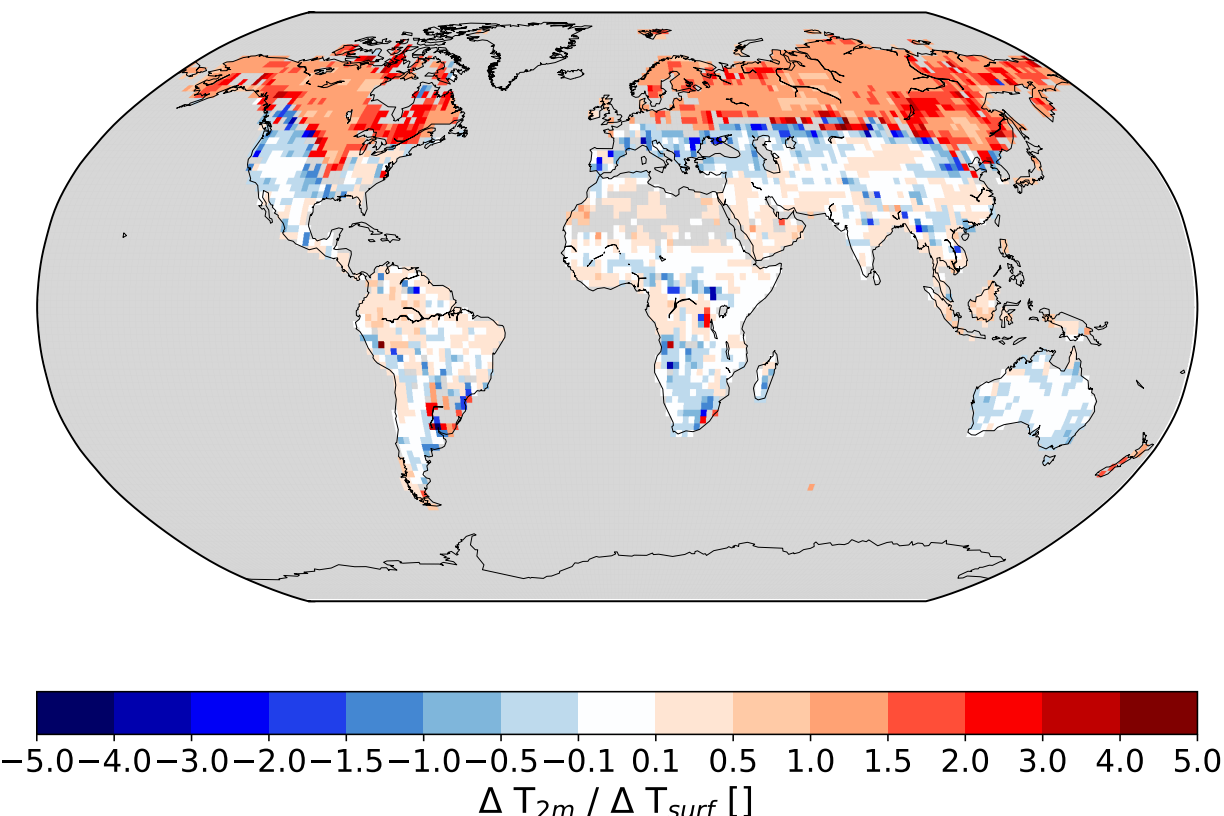

Figure S3: Local effects of deforestation in the MPI-ESM, annual mean 2m-air temperature divided by surface temperature. Values below zero indicate areas where the responses of the two variables differ in sign. Values above one indicate areas where $2 \mathrm{~m}$-air temperature responds stronger than surface temperature. 

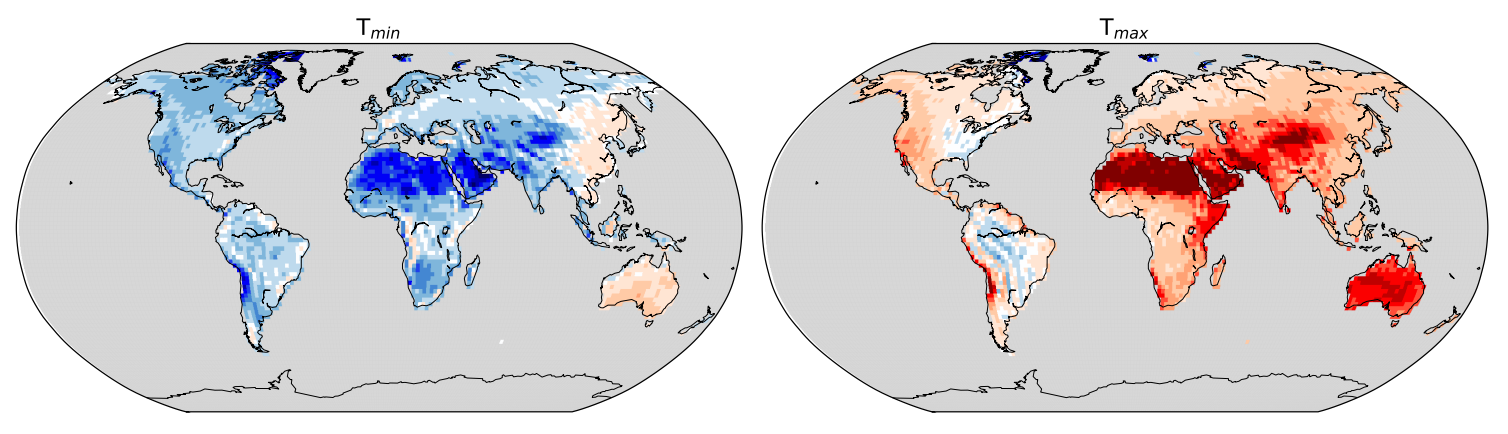

$-5.0$
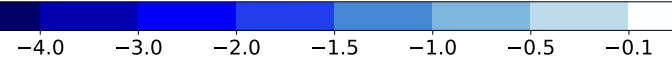

$\Delta \mathrm{T}[\mathrm{K}]$

Figure S4: $\mathrm{T}_{\text {surf }}-\mathrm{T}_{\mathrm{atm}}$ as a measure of near-surface atmospheric instability, separately for nighttime and daytime conditions in the 'forest world' simulation. During nighttime, the surface is cooler than the lowest atmospheric layer in most regions. During daytime, the surface is warmer than the lowest atmospheric layer in most regions. In the maps, some regions exhibit a different sign than the rest of the world, possibly because the comparison here is not perfectly consistent: $\mathrm{T}_{\min }$ and $\mathrm{T}_{\max }$ at the surface may be reached earlier than in the lowest atmospheric layer. However, in the main text only differences between the forests and grasslands are considered, and a possibly different timing of $\mathrm{T}_{\min }$ and $\mathrm{T}_{\max }$ matters less for this difference.

a) $T_{\min }$

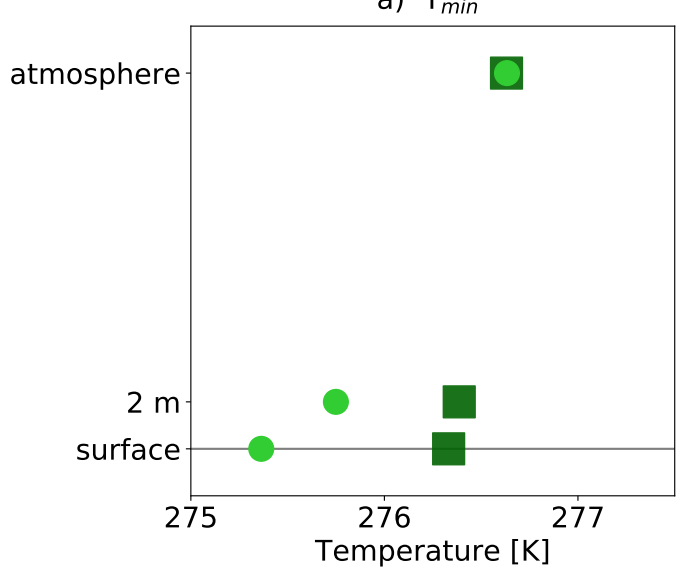

b) $\mathrm{T}_{\max }$

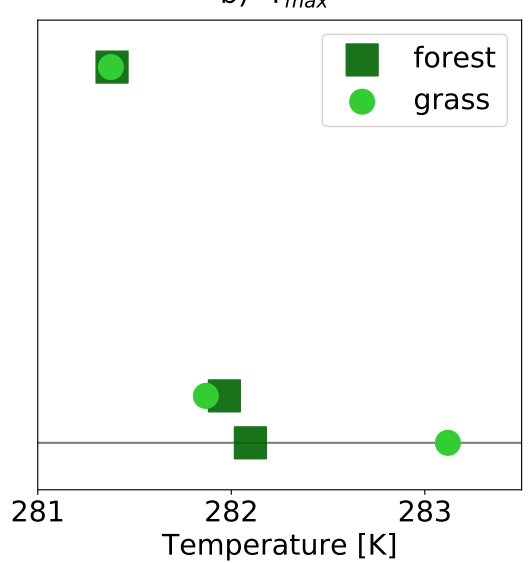

Figure S5: Illustration of the local effects of deforestation in the mid-latitudes on different temperature variables in the MPI-ESM, separately for a) mean daily minimum temperature, and b) mean daily maximum temperature. The 'forest' values are taken from the forest world simulation and the 'grass' values are the 'forest' values plus the local effects of deforestation on the respective variable. Values are averaged over mid-latitude areas $\left(40-60^{\circ} \mathrm{N}\right)$ that experienced intense deforestation $(\geq 15 \%)$ since 1860 . 

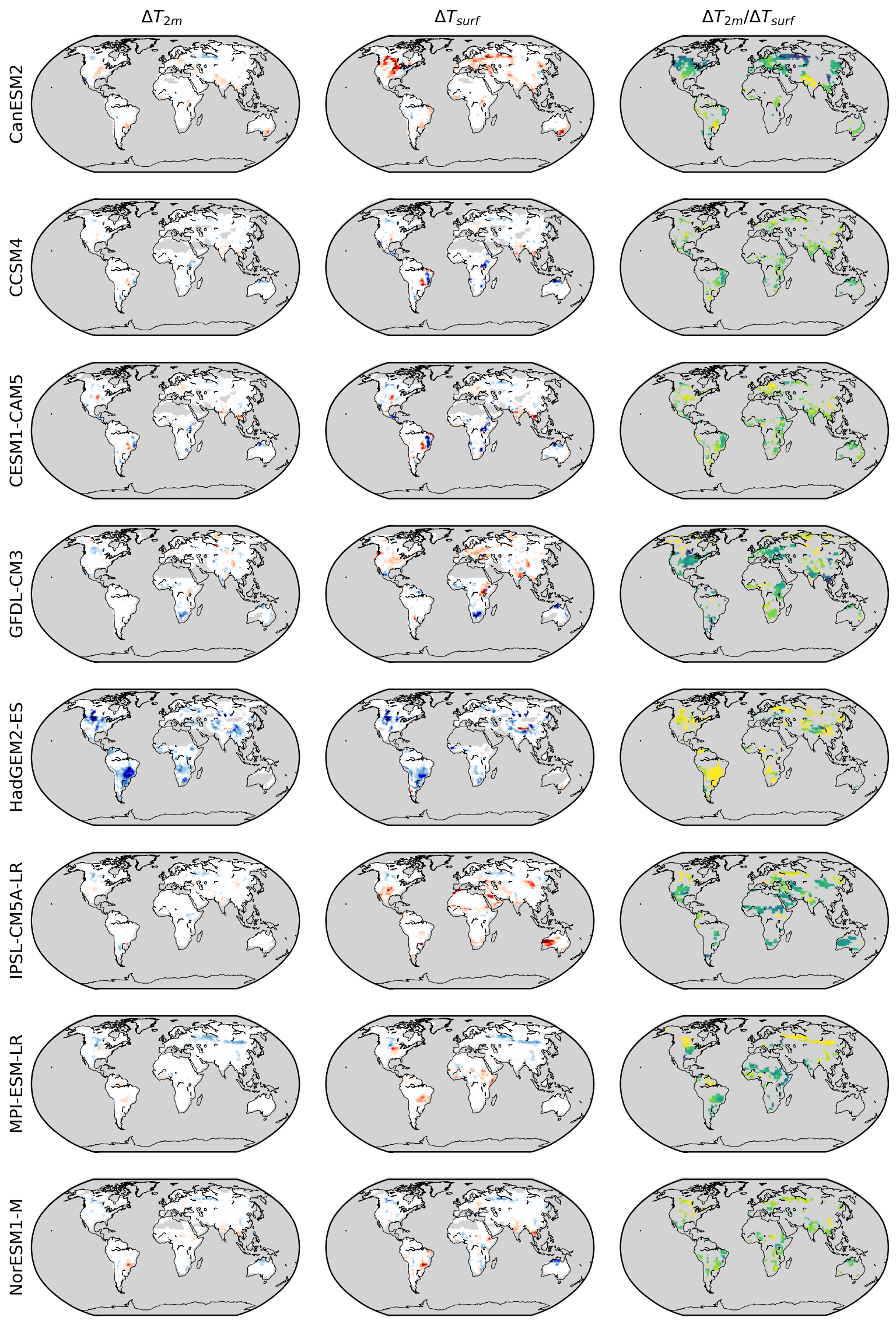

$-0.9-0.8-0.7-0.6-0.5-0.4-0.3-0.2-0.10 .10 .20 .30 .40 .50 .60 .70 .80 .9$ $\Delta$ Temperature $[\mathrm{K}]$ ratio []

Figure S6: Maps for the annual means from which the averages in Fig. 3 and Table S1 were obtained. Local deforestation response of near-surface air temperature (left), surface temperature (middle) and the ratio between the two (right). 



$\begin{array}{lllllllllllll}-0.9-0.8-0.7-0.6-0.5-0.4-0.3-0.2-0.10 .1 & 0.2 & 0.3 & 0.4 & 0.5 & 0.6 & 0.7 & 0.8 & 0.9\end{array}$ $\Delta$ Temperature $[\mathrm{K}]$

Figure S7: Maps for the northern-hemispheric wigter (DJF) means from which the averages in Fig. 3 and Table S1] were obtained. Local deforestation response of near-surface air temperature (left), surface temperature (middle) and the ratio between the two (right). 

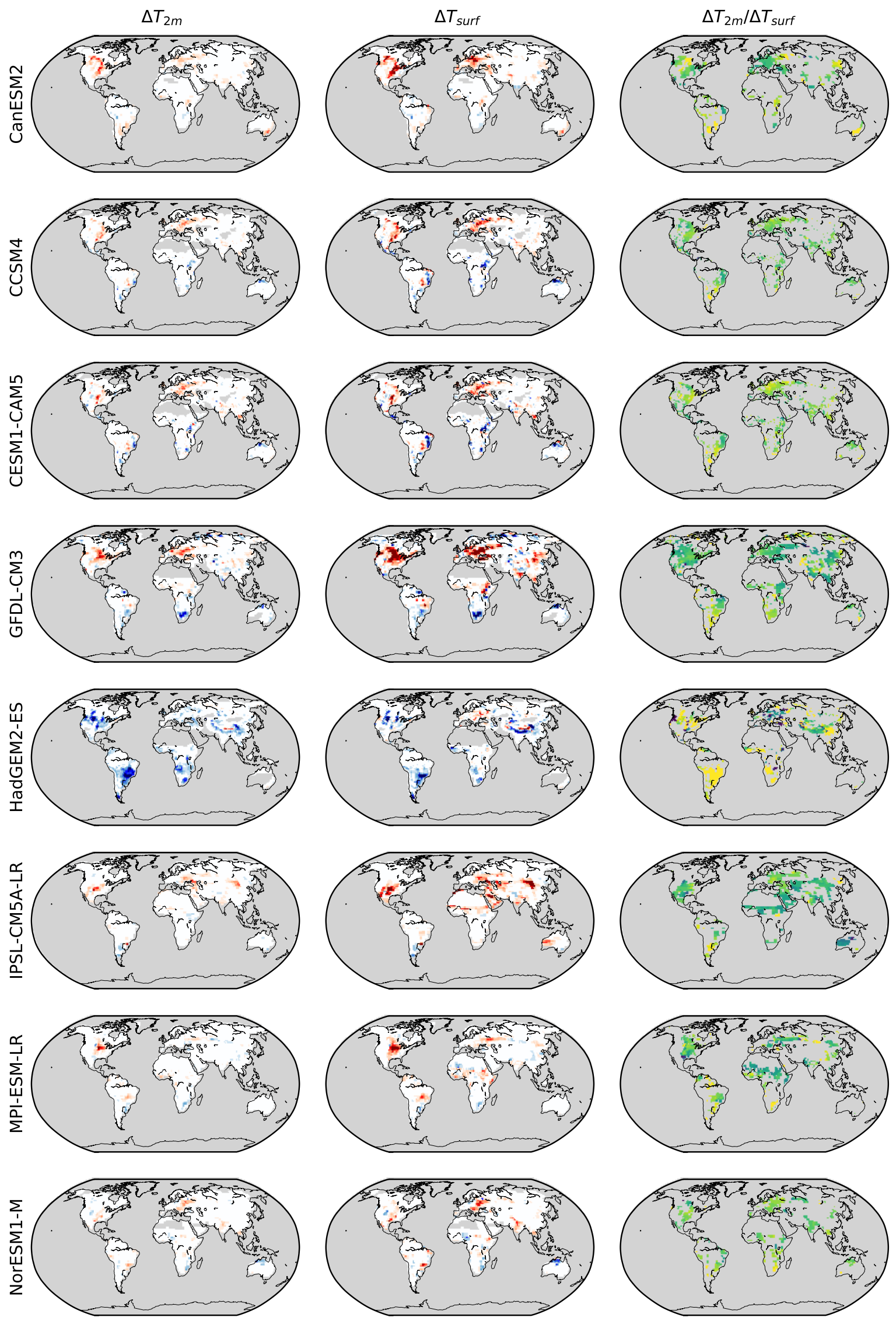

$\begin{array}{llllllllllllll}-0.9-0.8-0.7-0.6-0.5-0.4-0.3-0.2-0.10 .1 & 0.2 & 0.3 & 0.4 & 0.5 & 0.6 & 0.7 & 0.8 & 0.9\end{array}$ $\Delta$ Temperature $[\mathrm{K}]$

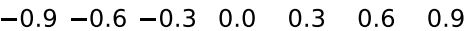
ratio []

Figure S8: Maps for the northern-hemispheric sū̄mer (JJA) means from which the averages in Fig. 3 and Table S1 were obtained. Local deforestation response of near-surface air temperature (left), surface temperature (middle) and the ratio between the two (right). 

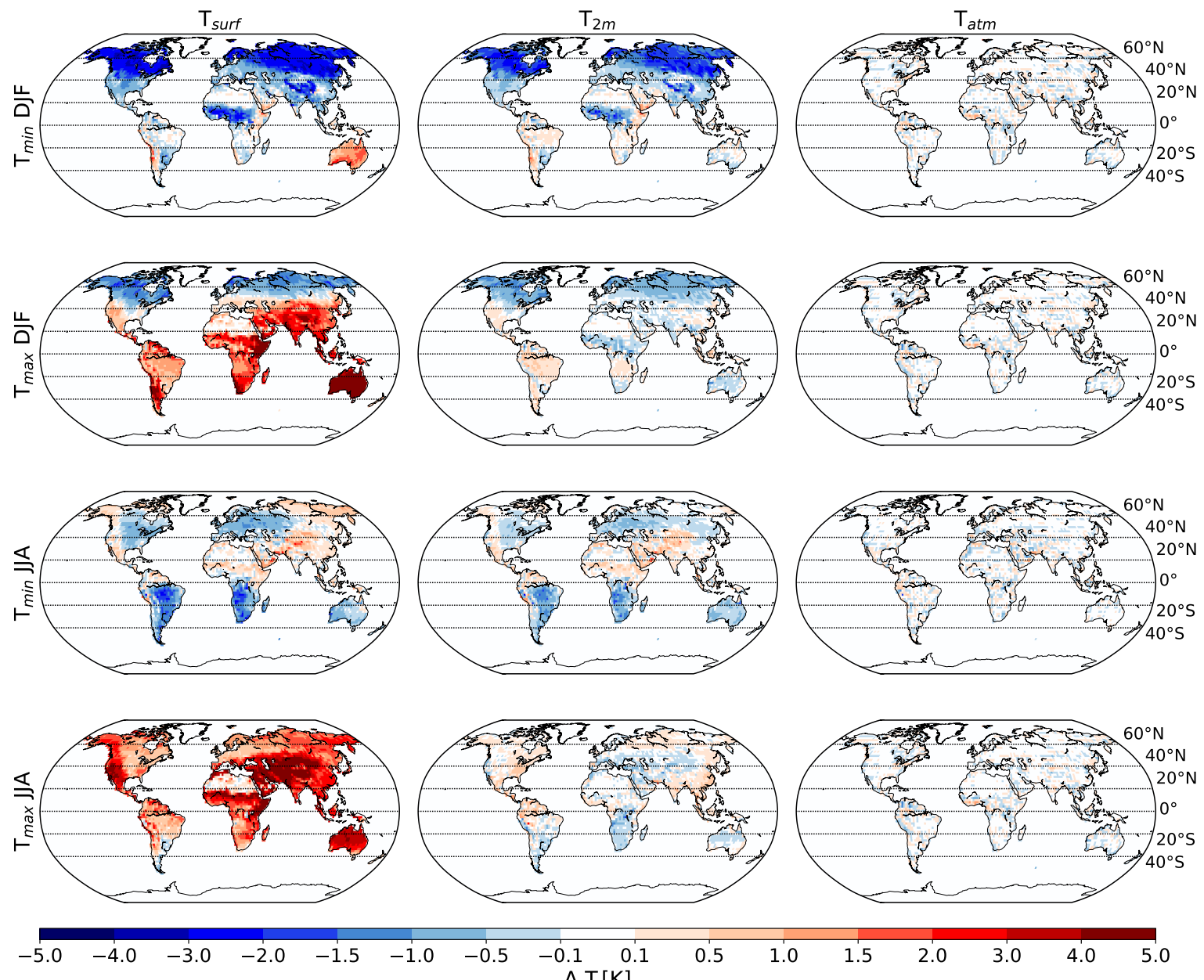

Figure S9: Temperature response to the local effects of deforestation, separately for minimum and maximum temperature during boreal winter $\left(\mathrm{T}_{\min } \mathrm{DJF}\right.$ and $\left.\mathrm{T}_{\max } \mathrm{DJF}\right)$ and summer $\left(\mathrm{T}_{\min }\right.$ JJA and $\left.\mathrm{T}_{\max } \mathrm{JJA}\right)$. 


\section{${ }_{17}$ References}

Pongratz, J., Reick, C. H., Raddatz, T., and Claussen, M. (2008). A reconstruction of global agricultural areas and land cover for the last millennium. Global Biogeochemical Cycles, 22:1-16. 